\title{
Investigation of Neutrophil-to-Lymphocyte Ratio, Platelet-to-Lymphocyte Ratio and Mean Platelet Volume in Patients with Compensated Heart Failure
}

\author{
Mustafa Yurtdaş' (D), Mahmut Özdemir² (D), Nesim Aladağ² (D) \\ ${ }^{1}$ Clinic of Cardiology, Balıkesir Sevgi Hospital, Balıkesir, Turkey \\ 2Department of Cardiology, Health Sciences University Van Training and Research Hospital, Van, Turkey
}

Cite this article as: Yurtdaş M, Özdemir M, Aladağ N. Investigation of Neutrophil-to-Lymphocyte Ratio, Platelet-to-Lymphocyte Ratio and Mean Platelet Volume in Patients with Compensated Heart Failure. JAREM 2018; 8(2): 67-71.

\begin{abstract}
Objective: Inflammation plays an important role in the pathogenesis of cardiovascular diseases. Neutrophil-to-lymphocyte ratio (NLR), plateletto-lymphocyte ratio (PLR), and mean platelet volume (MPV) are associated with inflammation; therefore, we aimed to evaluate NLR, PLR, and MPV; investigate their association with each other in patients with compensated heart failure (HF) and compare it with that in controls; and search the predictive value of those markers in detecting the presence of HF.

Methods: Between January 2016 and February 2017, 40 HF patients with left ventricular ejection fraction (LVEF) of <40\% were enrolled in the study. The control group comprised 30 individuals with LVEF of $\geq 50 \%$ and no HF. The NLR, PLR, and MPV values were evaluated in all participants. Results: Neutrophil-to-lymphocyte ratio, PLR, and MPV were significantly higher in the HF group than those in the control group. In the patient group, there was a significant inverse correlation between LVEF and all inflammatory markers (for all, $p<0.05$ ), except for MPV. Inflammatory markers showed a significant positive relationship with each other (for all, $\mathrm{p}<0.05$ ). Of all inflammatory markers, PLR was the only predictor of the presence of HF $(O R, 1.015 ; 95 \% \mathrm{Cl}: 1.001-1.028 ; \mathrm{p}=0.030)$. ROC curve analysis showed that the PLR value predicting the presence of $\mathrm{HF}$ was 73 with maximal sensitivity of $83 \%$ and specificity of $53 \%$ (UAC: $0.76 ; 95 \% \mathrm{Cl}: 0.65-0.88 ; \mathrm{p}<0.001)$.

Conclusion: Compared to those in the control group, NLR, PLR, and MPV were significantly higher and positively correlated to each other in the HF group. In addition, of those markers, only PLR could predict the presence of HF.

Keywords: Heart failure, neutrophil-to-lymphocyte ratio, platelet-to-lymphocyte ratio, mean platelet volume
\end{abstract}

\section{INTRODUCTION}

Heart failure (HF) is a major public health concern affecting $>23$ million people globally, and its prevalence increases with aging. Estimated 5-year and 10-year survival rates after HF diagnosis are $50 \%$ and $10 \%$, respectively. Mortality rates remain high despite advanced modern treatment modalities. Moreover, patients with $\mathrm{HF}$ require long-term care since it is a chronic condition that can progress with acute exacerbations (1).

Inflammation is known to play an important role in the pathogenesis of atherosclerosis and consequently of cardiovascular diseases (2). The role of inflammation in HF has been shown in several previous studies. HF syndrome is mainly associated with the imbalance between inflammatory and anti-inflammatory forces (3).

Recent studies have shown that ratios of neutrophil and platelet counts to lymphocyte count (neutrophil-to-lymphocyte ratio, NLR and platelet-to-lymphocyte ratio, PLR) were potential inflammatory markers that are closely related to the prognosis of chronic inflammatory and cardiovascular diseases (4-12). In addition, NLR and PLR parameters were associated with C-reactive protein (CRP), interleukin-6 (IL-6), and tumor necrosis factor-alpha (TNF- $\alpha$ ) values that play an important role in the pathogenesis of HF (5-11).

Mean platelet volume (MPV) is considered as an indicator of platelet function and activation, and high MPV values are shown to be an independent risk factor for several cardiovascular diseases including acute myocardial infarction and HF (13, 14). Moreover, high MPV values that are positively correlated with CRP were found in certain systemic inflammatory diseases $(15,16)$. To the best of our knowledge, a study investigating NLR, PLR, and MPV parameters simultaneously as inflammatory markers in HF, which is a systemic inflammatory condition, is not available. The aim of the present study was to investigate inflammatory markers (NLR, PLR, and MPV) in patients with compensated HF in comparison to individuals without HF and to evaluate intermarker correlations and their predictive values for the presence of HF. 


\section{METHODS}

This was a retrospectively designed study. Forty patients treated and followed up for compensated HF between January 2016 and February 2017 were included in the study. Compensated HF was described as the absence of HF-related dyspnea and congestion during the last month with a left ventricular ejection fraction (LVEF) $<40 \%$. The control group consisted of 30 patients with a $50 \%$ LVEF and without HF history who were admitted to the cardiology outpatient clinic. Body mass index (BMI), current medications, history of diabetes and hypertension, history of angioplasty and/or coronary bypass, and thorough physical examination findings were recorded for all subjects. Subjects with active infections, uncontrolled diabetes or hypertension conditions, BMI $\geq 30 \mathrm{~kg} / \mathrm{m}^{2}$, advanced stage hepatic or renal disease, acute and/ or chronic lung disease, moderate-severe valvular heart disease, cardiac arrhythmia except atrial fibrillation (AF), history of valvular replacement surgery and subjects with a history of any surgical operation, acute coronary syndrome, and/or coronary revascularization in the last 6 months were excluded from the study. All existing renal function test, electrolytes, and blood count test results of venous blood samples of the patients were assessed. Gender, age, leukocyte count, neutrophil count, platelet count, MPV, and high-sensitivity C-reactive protein (hsCRP) values of the patients were recorded. NLR was calculated by dividing neutrophil count to lymphocyte count; PLR was calculated by dividing platelet count to lymphocyte count. Our study was approved by the ethics committee of the Van District Training and Research Hospital in compliance with the Declaration of Helsinki. Informed consent was not obtained from the patients since this was a retrospective study.

\section{Echocardiographic Analysis}

Two-dimensional transthoracic echocardiography (ClearVue 550; Philips, Andover, MA, USA) was performed on all study subjects by an experienced cardiologist. Standard measurements as recommended by the American Society of Echocardiography were applied. LV diastolic and systolic diameters and interventricular and posterior wall thicknesses were measured using an M-mode in the parasternal long axis. Measurements in apical two-chamber views were used to calculate LVEF and end-diastolic and end-systolic volumes with the modified Simpson method.

\section{Statistical Analysis}

Statistical analyses were performed using the Statistical Package for Social Sciences 17.0 software (SPSS, Chicago, IL, USA). Descriptive data were presented as mean \pm standard deviation and percent (\%). Chi-square test was used for comparison of categorical data. Normality testing for continuous data was performed using the Kolmogorov-Smirnov test. Normally distributed data were compared using Student's t-test, whereas nonnormally distributed data were compared using Mann-Whitney $U$ test. Correlations between variables were assessed using Pearson's or Spearman's correlation tests. Multivariate regression analysis was performed to identify the predictors for HF. The prediction point values for predictive parameters were calculated using the receiver operating characteristic (ROC) curve analysis. A p value $<0.05$ was considered significant.

\section{RESULTS}

The demographic characteristics and echocardiographic findings for patients with HF and control subjects are shown in Table 1. Both groups were similar in terms of age, gender distribution, and BMI values. The prevalence of hypertension, hyperlipidemia, diabetes mellitus, and AF rhythm was significantly higher in the HF group. Patients with HF had significantly higher end-diastolic and end-systolic diameters and significantly lower LVEF than control subjects. Additionally, the current medications of both groups are shown in Table 2. Table 3 shows the laboratory data for both groups. Although serum creatinine levels and white blood cell counts were similar in both groups, NLR, PLR, MPV, and hsCRP were significantly higher in the HF group. The correlation analysis of the patient group demonstrated a significant negative correlation between LVEF and all inflammatory parameters except MPV (Table 4). Moreover, novel inflammatory markers showed a positive correlation between each other and with hsCRP (Table 4).

The described relationship was not observed in the control group. Multivariate regression analysis demonstrated that hypertension, $A F$, and only PLR among the inflammatory markers were predictive of $\mathrm{HF}$ (estimated risk ratio 1.015; 95\% confidence interval (CI) 1.001-1.028; $p=0.030$ ) (Table 5). The ROC curve analysis showed that a PLR value of 73 was predictive of HF with $83 \%$ sensitivity and $53 \%$ specificity (area under the curve $0.76 ; 95 \% \mathrm{Cl}$ 0.65-088; $p<0.001$ ) (Figure 1).

\section{DISCUSSION}

Our study results showed that patients with HF had higher NLR, PLR, and MPV values than controls, and these inflammatory markers were positively correlated with each other and hsCRP values. Among these inflammatory markers, only PLR was predictive of HF.

Chronic HF is a chronic inflammatory condition. Increased blood levels of inflammatory markers are associated with poor outcome in $\mathrm{HF}$, as in many chronic diseases. Increased inflammatory stimulus causes the release of many inflammatory cytokines including TNF- $\alpha$, IL- 6 , and CRP. Such inflammatory cytokines cause myocardial damage, leading to reduced left ventricular function and thus $\operatorname{HF}(2,3)$. White blood cells and their subsets are significant inflammatory markers in cardiovascular diseases. High neutrophil levels indicate inflammatory response, whereas low lymphocyte count indicates poor overall health status and increased physiological stress. Both low lymphocyte count and high neutrophil count are important risk factors that are predictive of reduced survival in patients with $\mathrm{HF}(4,7)$. In addition, in a previous study, high NLR values were found to be associated with increased mortality rates in subjects with decompensated HF, and the predictive value of NLR for mortality was found to be higher than that of total white blood cell count and slightly low lymphocyte count (7). Therefore, NLR has a significant prognostic value in HF. On the other hand, previous studies have shown that increased platelet and decreased lymphocyte counts were associated with poor cardiovascular outcomes $(8,11,12)$. Similarly, in our study, we observed that subjects with HF have higher NLR and PLR values than controls, and most importantly, these parameters were closely associated with hsCRP, which is considered as the first marker of inflammation. According to the multivariate regression 
Table 1. Demographic and echocardiographic findings of the patient and control groups

\begin{tabular}{|c|c|c|c|}
\hline Variables & $\begin{array}{c}\text { Patient } \\
\text { group } \\
(n=40)\end{array}$ & $\begin{array}{l}\text { Control } \\
\text { group } \\
(n=30)\end{array}$ & $p$ \\
\hline \multicolumn{4}{|l|}{ Demographic findings } \\
\hline Age (years) & $69 \pm 12$ & $66 \pm 7$ & 0.238 \\
\hline Female gender, $n(\%)$ & $21(53)$ & $18(60)$ & 0.532 \\
\hline Hypertension, n (\%) & $24(60)$ & $7(23)$ & 0.002 \\
\hline Diabetes mellitus, n (\%) & $12(30)$ & $3(10)$ & 0.016 \\
\hline Hyperlipidemia, n (\%) & $16(40)$ & $4(13)$ & 0.015 \\
\hline Body mass index (kg/m2) & $26.1 \pm 2.3$ & $27.0 \pm 1.6$ & 0.122 \\
\hline Atrial fibrillation, $n(\%)$ & $17(43)$ & $2(7)$ & 0.001 \\
\hline PCl history, n (\%) & $27(68)$ & 0 & $<0.001$ \\
\hline Coronary bypass history, n (\%) & $9(23)$ & 0 & 0.005 \\
\hline Non-ischemic HF, n (\%) & $5(20)$ & 0 & 0.044 \\
\hline \multicolumn{4}{|l|}{ Echocardiographic findings } \\
\hline End-diastolic diameter $(\mathrm{cm})$ & $62 \pm 7$ & $45 \pm 4$ & $<0.001$ \\
\hline End-systolic diameter (cm) & $43 \pm 5$ & $30 \pm 3$ & $<0.001$ \\
\hline Ejection fraction (\%) & $33 \pm 5$ & $63 \pm 6$ & $<0.001$ \\
\hline
\end{tabular}

Table 2. Current medications in both groups

\begin{tabular}{|l|c|c|c|}
\hline Variables & $\begin{array}{c}\text { Patient } \\
\text { group } \\
(\mathbf{n = 4 0 )}\end{array}$ & $\begin{array}{c}\text { Control } \\
\text { group } \\
(\mathbf{n = 3 0 )}\end{array}$ & $\mathbf{p}$ \\
\hline Diuretics, $\mathrm{n}(\%)$ & 30 & 0 & $<0.001$ \\
\hline Beta-blockers, $\mathrm{n}(\%)$ & 28 & 10 & 0.002 \\
\hline Calcium channel blockers, $\mathrm{n}(\%)$ & 9 & 4 & 0.329 \\
\hline ACEl-ARB ( \pm thiazides), $\mathrm{n}(\%)$ & 35 & 24 & 0.006 \\
\hline Nitrates, $\mathrm{n}(\%)$ & 6 & 0 & 0.027 \\
\hline Digoxin, $\mathrm{n}(\%)$ & 11 & 0 & 0.002 \\
\hline Acetylsalicylic acid, $\mathrm{n}(\%)$ & 25 & 5 & $<0.001$ \\
\hline Clopidogrel, $\mathrm{n}(\%)$ & 15 & 1 & $<0.001$ \\
\hline Oral anticoagulants, $\mathrm{n}(\%)$ & 17 & 1 & $<0.001$ \\
\hline
\end{tabular}

analysis we performed, although predictive values of NLR and MPV for predicting HF have not reached adequate statistical significance, PLR showed a statistically significant predictive value for the presence of HF. Similarly, in our study, LVEF was found to be negatively correlated with NLR and PLR, whereas there was no association with MPV. Our results were confirmed by Durmus et al. (4); they reported that patients with decompensated HF have higher NLR and PLR values, which were significant inflammatory markers for predicting the presence of $\mathrm{HF}$, than controls, and
Table 3. Laboratory findings of both groups

\begin{tabular}{|l|c|c|c|}
\hline Variables & $\begin{array}{c}\text { Patient } \\
\text { group } \\
(\mathbf{n = 4 0})\end{array}$ & $\begin{array}{c}\text { Control } \\
\text { group } \\
(\mathbf{n}=\mathbf{3 0})\end{array}$ & $\mathbf{p}$ \\
\hline Creatinine $(\mathrm{mg} / \mathrm{dL})$ & $0.92 \pm 0.20$ & $0.88 \pm 0.11$ & 0.511 \\
\hline hsCRP $(\mathrm{mg} / \mathrm{L})$ & $3.5 \pm 2.2$ & $2.4 \pm 1.9$ & 0.032 \\
\hline Leukocyte count $\left(\times 10^{3} / \mathrm{mm}^{3}\right)$ & $7.4 \pm 1.4$ & $7.2 \pm 1.3$ & 0.705 \\
\hline Neutrophil count $\left(\times 10^{3} / \mathrm{mm}^{3}\right)$ & $4.6 \pm 1.2$ & $4.0 \pm 1.1$ & 0.034 \\
\hline Lymphocyte count $\left(\times 10^{3} / \mathrm{mm}^{3}\right)$ & $1.8 \pm 0.8$ & $2.4 \pm 1.8$ & 0.005 \\
\hline Platelet count $\left(\times 10^{3} / \mathrm{mm}^{3}\right)$ & $253 \pm 90$ & $178 \pm 61$ & $<0.001$ \\
\hline NLR & $3.2 \pm 1.4$ & $2.4 \pm 1.8$ & 0.042 \\
\hline PLR & $179 \pm 125$ & $101 \pm 82$ & 0.004 \\
\hline Mean platelet volume (fL) & $8.9 \pm 2.4$ & $7.7 \pm 1.4$ & 0.011 \\
\hline hsCRP: high-sensitivity C-reactive protein; & NLR: neutrophil- \\
to-lymphocyte ratio; PLR: platelet-to-lymphocyte ratio.
\end{tabular}

Table 4. Evaluation of intermarker correlation and correlation between inflammatory markers and LVEF

\begin{tabular}{|l|c|c|c|c|c|}
\hline Variables & NLR & PLR & MPV & hsCRP & LVEF \\
\hline NLR & - & $p<0.001$ & $p=0.038$ & $p<0.001$ & $p=0.004$ \\
\hline & & $r=0.751$ & $r=0.329$ & $r=0.543$ & $r=-0.451$ \\
\hline PLR & $p<0.001$ & - & $p=0.001$ & $p=0.011$ & $p=0.036$ \\
\hline & $r=0.751$ & & $r=0.487$ & $r=0.400$ & $r=-0.400$ \\
\hline MPV & $p=0.038$ & $p=0.001$ & - & $p<0.001$ & $p=0.065$ \\
\hline hsCRP & $r=0.329$ & $r=0.487$ & & $r=0.801$ & \\
\hline & $p<0.001$ & $p=0.011$ & $p<0.001$ & - & $p=0.032$ \\
\hline & $r=0.543$ & $r=0.400$ & $r=0.801$ & & $r=-0.381$ \\
\hline $\begin{array}{l}\text { LVEF: left ventricular ejection fraction; hsCRP: high-sensitivity } \\
\text { C-reactive protein; NLR: neutrophil-to-lymphocyte ratio; } P \text { : } \\
\text { platelet-to-lymphocyte ratio; MPV: mean platelet volume }\end{array}$
\end{tabular}

high NLR values are an independent predictor for death after a mean follow-up of 12 months. In their study, although LVEF had a negative correlation with NLR, no correlation was found with PLR. The major limitation of this study was the lack of CRP, which is considered as a primary inflammatory marker in clinical practice, assessments. In our study, we evaluated hsCRP and also MPV that is a novel inflammatory marker. The partial discordance of our study results may be explained by small sample of patients and dissimilarity of patients with HF in terms of both clinical and/or echocardiographic features and different study designs. In contrast to our results, in the study by Kaya et al. (14), MPV was found to be an independent predictor of hospitalization due to HF in patients with decompensated HF. In their study, a significant proportion of the patients had chronic obstructive pulmonary disease (COPD, 32\%) and right HF (55\%). Lower MPV levels are observed in high-grade inflammatory diseases, whereas higher 
Table 5. Results of multivariate analysis to determine the predictors of heart failure

\begin{tabular}{|l|c|c|c|}
\hline Variables & \multicolumn{3}{|c|}{ Multivariate analysis } \\
\hline $\begin{array}{c}\text { Estimated } \\
\text { risk ratio }\end{array}$ & $\begin{array}{c}95 \% \text { confidence } \\
\text { interval }\end{array}$ & p \\
\hline Hypertension & 4.985 & $1.331-18.673$ & 0.017 \\
\hline Hyperlipidemia & 2.480 & $0.348-17.674$ & 0.365 \\
\hline Diabetes mellitus & 3.906 & $0.342-44.662$ & 0.125 \\
\hline Atrial fibrillation & 7.075 & $1.147-43.620$ & 0.035 \\
\hline hsCRP & 0.985 & $0.704-1.377$ & 0.911 \\
\hline NLR & 0.644 & $0.317-1.309$ & 0.224 \\
\hline PLR & 1.015 & $1.001-1.028$ & 0.030 \\
\hline Hypertension & 4.985 & $1.331-18.673$ & 0.017 \\
\hline hsCRP: high-sensitivity C-reactive protein; NLR: neutrophil-to- \\
lymphocyte ratio; PLR: platelet-to-lymphocyte ratio \\
\hline
\end{tabular}

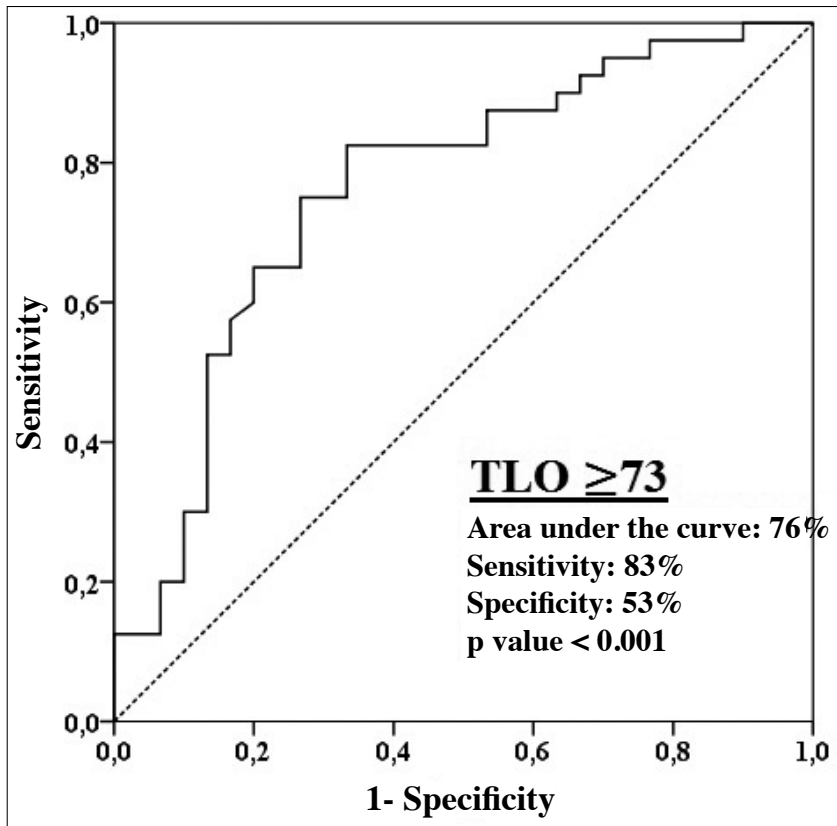

Figure 1. ROC curve analysis of PLR as a predictor of heart failure

MPV levels are seen in low-grade inflammatory diseases. Since COPD is considered as a high-grade inflammatory disease, lower MPV levels can be expected. However, MPV was found to be significantly higher in this study, which is most probably due to the presence of both left and right HF. Patients in our study group had symptoms compatible with patients with chronic compensated HF without COPD and right HF findings. Although MPV failed to predict $\mathrm{HF}$ in our study, it was significantly higher in patients with HF than in control subjects and was positively correlated with NLR, PLR, and hsCRP. These findings suggest that MPV plays an important role in the pathogenesis of compensated HF that has chronic low-grade inflammation features.

Among the inflammatory markers, statistical significance of only PLR in predicting the presence of HF can be explained by two conditions. First, the majority of patients with HF included in the study had underlying coronary artery disease. Some studies have shown that PLR has higher prognostic value than NLR. Oylumlu et al. (12) reported that PLR is superior to NLR in predicting inhospital deaths in patients with acute coronary syndrome and shows a negative correlation with LVEF. Second, a substantial proportion of our patients had AF (43\%). Patients with AF were shown to manifest more atrial inflammatory patch, fibrosis, and myositis necrosis than those without (17). AF can induce inflammation by increasing platelet activity and decreasing blood viscosity (11). High PLR is known to be associated with increased fibrinogen, which can lead to reduced blood viscosity and tissue oxygenation (11). All these data indicate an association between AF and high PLR.

\section{CONCLUSION}

Neutrophil-to-lymphocyte ratio (NLR), PLR, and MPV, which are low cost, easily available novel inflammatory markers, were significantly higher in patients with HF and showed a positive correlation with each other. Additionally, among these markers, only PLR could predict the presence of HF.

Ethics Committee Approval: Ethics committee approval was received for this study from the ethics committee of Van Region Training and Research Hospital.

Informed Consent: Informed consent was not taken from patients due to the retrospective nature of the study.

Peer-review: Externally peer-reviewed.

Author Contributions: Concept - M.Y., M.Ö., N.A.; Design - M.Y., M.Ö., N.A.; Supervision - M.Y., M.Ö., N.A.; Resources - M.Y., M.Ö.; Materials - M.Y.; Data Collection and/or Processing - M.Y., M.Ö.; Analysis and/or Interpretation - M.Y., M.Ö., N.A.; Literature Search - M.Y., M.Ö., N.A.; Writing Manuscript - M.Y., M.Ö.; Critical Review - M.Y., M.Ö., N.A.; Other - M.Y., M.Ö.

Conflict of Interest: Authors have no conflicts of interest to declare.

Financial Disclosure: The authors declared that this study has received no financial support.

\section{REFERENCES}

1. Véronique LR. Epidemiology of Heart Failure. Circ Res 2013; 113: 646-59. [CrossRef]

2. Shrivastava AK, Singh HV, Raizada A, Singh SK. C-reactive protein, inflammation and coronary heart disease. Egypt Heart J 2014; 67: 89-97. [CrossRef]

3. Oikonomou E, Tousoulis D, Siasos G, Zaromitidou M, Papavassiliou AG, Stefanadis C. The role of inflammation in heart failure: new therapeutic approaches. Hellenic J Cardiol 2011; 52: 30-40.

4. Durmus E, Kivrak T, Gerin F, Sunbul M, Sari I, Erdogan O. Neutrophilto-Lymphocyte Ratio and Platelet-to-Lymphocyte Ratio are Predictors of Heart Failure. Arq Bras Cardiol 2015; 105: 606-13. [CrossRef]

5. Yurtdaş M, Yaylali YT, Kaya Y, Ozdemir M, Ozkan I, Aladağ N. Neutrophil-to-Lymphocyte Ratio May Predict Subclinical Atherosclerosis in $\mathrm{Pa}$ tients with Psoriasis. Echocardiography 2014; 31: 1095-104. [CrossRef]

6. Yurtdaş M, Yaylali YT, Aladağ N, Özdemir M, Ceylan Y, Gençaslan M, et al. Heart rate recovery after exercise and its relation with neutrophil-to-lymphocyte ratio in patients with cardiac syndrome $\mathrm{X}$. Coron Artery Dis. 2014; 25: 485-92. [CrossRef]

7. Uthamalingam S, Patvardhan EA, Subramanian S, Ahmed W, Martin $W$, Daley $M$, et al. Utility of the neutrophil to lymphocyte ratio in pre- 
dicting long-term outcomes in acute decompensated heart failure. Am J Cardiol 2011; 107: 433-8. [CrossRef]

8. Yildiz A, Yuksel M, Oylumlu M, Polat N, Akyuz A, Acet $H$, et al. The utility of the platelet-lymphocyte ratio for predicting no reflow in patients with ST-segment elevation myocardial infarction. Clin Appl Thromb Hemost 2015; 21: 223-8. [CrossRef]

9. Turkmen K, Güney I, Yerlikaya FH, Tonbul HZ. The relationship between neutrophil-to-lymphocyte ratio and inflammation in end stage renal disease patients. Renal Failure 2012; 34: 2: 155-9. [CrossRef]

10. Turkmen K, Erdur FM, Ozcicek F, Ozcicek A, Akbas EM, Ozbicer A, et al. Platelet-to-lymphocyte ratio better predicts inflammation than neutrophil-to-lymphocyte ratio in end-stage renal disease patients. Hemodial Int 2013; 17: 391-6. [CrossRef]

11. Gary T, Pichler M, Belaj K, Hafner F, Gerger A, Froehlich H, et al. Platelet-to-lymphocyte ratio: a novel marker for critical limb ischemia in peripheral arterial occlusive disease patients. PLoS One 2013; 8: e67688. [CrossRef]

12. Oylumlu M, Yıldız A, Oylumlu M, Yüksel M, Polat N, Bilik MZ, et al. Platelet-to-lymphocyte ratio is a predictor of in-hospital mortality patients with acute coronary syndrome. Anatol J Cardiol 2015; 15 277-83. [CrossRef]

13. Liu X, Wang S, Yuan L, Chen F, Zhang L, Ye X, et al. Increased mean platelet volume is associated with higher in-hospital mortality rate in patients with acute myocardial infarction. Clin Lab 2017; 63: 163-7. [CrossRef]

14. Kaya H, Yıldırımlı MK, Kurt R, Beton O, Yilmaz MB. Mean platelet volume as a predictor of heart failure-related hospitalizations in stable heart failure outpatients with sinus rhythm. Acta Cardiol Sin 2017; 33: 292-300.

15. Yurtdaş M, Kaya Y, Özkan I. Psoriasisli hastalarda kalp hızı toparlanması ile ortalama trombosit hacmi arasındaki ilişkinin değerlendirilmesi. MN Cardiology 2012; 19: 177-81.

16. Akyol S, Çörtük M, Baykan AO, Kiraz K, Börekçi $A$, Şeker $T$, et al. Mean platelet volume is associated with disease severity in patients with obstructive sleep apnea syndrome. Clinics 2015; 70: 481-5. [CrossRef]

17. Frustaci A, Chimenti C, Bellocci F, Morgante E, Russo MA, Maseri A. Histological substrate of atrial biopsies in patients with lone atrial fibrillation. Circulation 1997; 96: 1180-4. [CrossRef] 